\title{
Regionalization of the Modified Bartlett-Lewis Rectangular Pulse Stochastic Rainfall Model
}

\author{
Dongkyun $\mathrm{Kim}^{1, *}$, Francisco Olivera ${ }^{2}$, Huidae $\mathrm{Cho}^{3}$, and Scott A. Socolofsky ${ }^{2}$ \\ ${ }^{1}$ School of Urban and Civil Engineering, Hongik University, Seoul, Republic of Korea \\ ${ }^{2}$ Zachry Department of Civil Engineering, Texas A\&M University, Texas, USA \\ ${ }^{3}$ Division of Climate Change and Special Initiatives, Dewberry, Virginia, USA
}

Received 10 April 2012, accepted 12 November 2012

\begin{abstract}
Parameters of the Modified Bartlett-Lewis Rectangular Pulse (MBLRP) stochastic rainfall simulation model were regionalized across the contiguous United States. Three thousand four hundred forty-four National Climate Data Center (NCDC) rain gauges were used to obtain spatial and seasonal patterns of the model parameters. The MBLRP model was calibrated to minimize the discrepancy between the precipitation depth statistics between the observed and MBLRP-generated precipitation time series. These statistics included the mean, variance, probability of zero rainfall and autocorrelation at 1-, 3-, 12- and 24-hour accumulation intervals. The Ordinary Kriging interpolation technique was used to generate maps of the six MBLRP model parameters for each of the 12 months of the year. All parameters had clear to discernible regional tendencies; except for one related to rain cell duration distribution. Parameter seasonality was not obvious and it was more apparent in some locations than in others, depending on the seasonality of the rainfall statistics. Cross-validation was used to assess the validity of the parameter maps. The results indicate that the suggested maps reproduce well the observed rainfall statistics for different accumulation intervals, except for the lag-1 autocorrelation coefficient. The boundaries of the expected residual, with $95 \%$ confidence, between the observed rainfall statistics and the simulated rainfall statistics based on the map parameters were approximately $\pm 0.064 \mathrm{~mm} \mathrm{hr}^{-1}, \pm 1.63 \mathrm{~mm}^{2} \mathrm{hr}^{-2}, \pm 0.16$, and \pm 0.030 for the mean, variance, lag- 1 autocorrelation and probability of zero rainfall at hourly accumulation levels, respectively. The estimated parameter values were also used to estimate the storm and rain cell characteristics.
\end{abstract}

Key words: Poisson cluster, Bartlett-Lewis, Stochastic rainfall model

Citation: Kim, D., F. Olivera, H. Cho, and S. A. Socolofsky, 2013: Regionalization of the modified Bartlett-Lewis Rectangular Pulse stochastic rainfall model. Terr. Atmos. Ocean. Sci., 24, 421-436, doi: 10.3319/TAO.2012.11.12.01(Hy)

\section{INTRODUCTION}

Precipitation variability in time and space strongly influences important water issues ranging from flooding to drought to availability (i.e., from excess water to lack of water). Drainage system design, the implementation of flood protection measures or the assessment of water availability for human consumption, irrigation or hydropower, for example, require extensive understanding of the precipitation patterns in the area. Depending on the type of problem being addressed and the size of the hydrologic system, sub-daily precipitation data might be required, which is not always available. In fact, according to the National Climate Data Center (NCDC) (2011a, b), as of 2006, there were 25396

\footnotetext{
* Corresponding author

E-mail: kim.dongkyun@hongik.ac.kr
}

rain gauges in the contiguous United States but only $25 \%$ of them keep sub-daily records (i.e., hourly). That is, on average, one gauge for each $1550 \mathrm{~km}^{2}$, but it can be even sparser in some areas of the country. In this context of lack of data with the desired temporal resolution, stochastic rainfall generators offer the possibility of producing synthetic precipitation time series that resemble the fundamental characteristics of the real precipitation, which can be used as input to hydrologic models.

This study addresses the regionalization of the parameters of the Modified Bartlett-Lewis Rectangular Pulse (MBLRP) stochastic point process rainfall model (Rodriguez-Iturbe et al. 1987, 1988), a stochastic rainfall generator, for the contiguous United States. Among the stochastic rainfall generators, the MBLRP model was selected because it 
"is particularly accessible to mathematical analysis" (Rodriguez-Iturbe et al. 1987). However, it is well documented that the MBLRP model has limitations for accurately representing extreme values for different accumulation intervals and zero-depth probabilities (e.g., Onof and Wheater 1994a; Verhoest et al. 1997; Cowpertwait 1998; Cameron et al. 2001). Maps of each model parameter for each month of the year were developed, which allow the simulation of subdaily rainfall at any point in the country without having to calibrate and validate the model each time. These maps, in raster format, are available for downloading at the first author's Internet site at http://huniv.hongik.ac.kr/ dekaykim/ MBLRP USA/MBLRP USA.zip. The regionalization of the MBLRP model parameters presented here has similar goals previous studies had, but it is fundamentally different in the robustness of its results because of the much larger number of rain gauges used for map generation and validation, and of the approach used in calibration for handling the multimodality of the MBLRP model structure.

Rodriguez-Iturbe et al. (1987) presented the BartlettLewis Rectangular Pulse (BLRP) model in which storm events arise in a Poisson process. Rodriguez-Iturbe et al. (1988) further modified the 5-parameter BLRP model by introducing an additional parameter to enhance its ability to capture dry periods and called it the Modified BartlettLewis Rectangular Pulse (MBLRP) model. Among others, Islam et al. (1990), Bo et al. (1994), Onof and Wheater (1994a), and Chandler (1997) discuss the complexity of the model calibration; and Islam et al. (1990), Bo et al. (1994), Onof and Wheater (1994b), Glasbey et al. (1995), Cowpertwait et al. (1996a), Khaliq and Cunnane (1996), Onof et al. (1996), and Verhoest et al. (1997) assess the overall accuracy of its fundamental assumptions by comparing statistics and extreme values of observed and synthetic precipitation time series. Verhoest et al. (1997), in particular, applied the MBLRP model to Uccle, Belgium, for which 27 years of 10-minute rainfall data were available. After calibrating their model using the mean, variance and probability of zero of the observed rainfall, synthetic time series were generated that successfully reproduced extreme values for long accumulation intervals but failed to do so for short accumulation intervals. They also noticed that the duration of the storms in the synthetic rainfall time series was shorter than that in the observed one, which was interpreted as a too intense clustering of rainfall events. Cowpertwait (1998) applied the MBLRP model to a site in Wellington, New Zealand, for which 41 years of hourly rainfall data were available and obtained a good fit for the observed extreme values for a range of accumulation intervals (e.g., 1 hour through 24 hours) when calibration was also based on the skewness of the precipitation distribution, in addition to the mean and variance. However, as he points out, including high-order moments do not affect the extreme value estimates if a twoparameter distribution - such as the Gumbel distribution, in which the parameters depend on the mean and variance only - is used. Cameron et al. (2001), likewise, propose a modified random pulse Barlett-Lewis stochastic rainfall model for extreme value simulations that uses a generalized pareto distribution to represent the high-intensity rain cells. Onof et al. (2000) discuss the importance of considering "the application for which the rainfall model is to be used" when assessing the relevance of the discrepancies between observed and synthetic rainfall. A further development of the MBLRP model is the MBLRP spatial-temporal model (Cox and Isham 1988; Cowpertwait 1998; Onof et al. 2000), which accounts for the spatial and temporal correlation and variability of the precipitation field.

Studies on the regionalization of point-process based stochastic rainfall simulation models (including the MBLRP model) have been conducted in past decades. An early attempt at regionalizing the parameters of the Hershenhorn and Woolhiser (1987) point-process rainfall model was conducted by Econopouly et al. (1990). Their study used data from two gauges, one in Missouri and one in Nebraska, and its results were compared to observed precipitation in three gauges, one in Illinois, one in Iowa and one in Wisconsin. They showed that parameter sets could be transferred up to $470 \mathrm{~km}$ away within the same climatological regime. Hawk and Eagleson (1992) regionalized the parameters of the MBLRP model across the country and generated contour maps of each parameter for each month of the year. Their maps were generated based on data from 75 randomly selected rain gauges and 4 additional gauges were used for validation. Cowpertwait et al. (1996b) suggest regression equations that relate the parameters of the Neyman-Scott Rectangular Pulse (NSRP) model (Rodriguez-Iturbe et al. 1987) to regional properties (e.g., altitude and distance to the coast). Their analysis was performed using rainfall data from 112 sites in the United Kingdom.

Other regionalization studies address rainfall disaggregation models in which coarse temporal precipitation time series are disaggregated into fine series. Gyasi-Agyei (1999) suggests a method for estimating the parameters of the Gyasi-Agyei and Willgoose (1997) disaggregation model for regions where only coarse temporal data are available. His analysis was performed with 13 rain gauges over a region of several hundred square kilometers in Australia. GyasiAgyei's (1999) approach generated rainfall time series that matched well observed precipitation depth statistics such as mean, variance, probability of zero and auto-correlation coefficient at different accumulation intervals ranging from 6 minutes to 24 hours. A more recent study on parameter regionalization of rainfall disaggregation is described in Gyasi-Agyei and Mahbub (2007). They implemented the approach of Gyasi-Agyei (1999) on the entire Australian continent using rainfall observations from 43 six-minute rain gauges. As in the previous case, the generated rainfall time series matched well observed precipitation depth sta- 
tistics at different accumulation intervals. Choi et al. (2008) applied Socolofsky et al.'s (2001) single-parameter rainfall disaggregation method to Texas. The method uses hourly precipitation records from one or more stations to simulate hourly precipitation at another station for which only daily data are available. They used a total of 532 hourly rain gauges that constituted a database of historical precipitation from which rainfall intermittence patterns were derived. The single parameter represented the smallest expected onehour event, and it was found to have a strong seasonal but a weak regional variability. Resulting simulated precipitation time series matched well observed precipitation statistics with the exception of high variances and high lag-one hour autocorrelation coefficients, which were systematically underestimated.

In this study, maps of each of the six MBLRP model parameters for each month of the year - for a total of 72 maps - have been developed for the contiguous United States. This result is particularly meaningful in that it enables the generation of the synthetic rainfall time series at any spatial location in the contiguous United States based on MBLRP model. According to the conventional framework, generating synthetic rainfall time series using MBLRP model at ungauged locations requires the following steps: (1) estimation of rainfall statistics at various temporal accumulation levels nearby rainfall gauges; (2) spatial interpolation of all calculated rainfall statistics for the location of interest; (3) estimation of the MBLRP model parameters using an optimization algorithm; and (4) generation of rainfall time series using the estimated parameters. Especially, the step (3) puts the major obstruction in the process because the typical slope-based optimization algorithm often fails, so using a heuristic optimization algorithm is essential, which requires a significant amount of effort to implement. This study overcame this issue by providing maps of the parameters which contains the predetermined parameter values at all spatial locations in the United States. Furthermore, the parameter values read from the maps were validated in their ability to reproduce the observed rainfall statistics at 3444 gauge locations through the technique of cross-validation, which solidifies and adds the unique value to the result of this study.

Because the parameter maps presented here were developed using the MBLRP temporal model, they should be used to estimate precipitation at a single point only. Regionalization of the MBLRP spatial-temporal model, for applications in larger areas, was out of the scope of this study, although it is recognized as an important matter for further research. Rainfall characteristics such as the average rainfall depth per storm, storm duration, number of rain cells per storm and rain cell duration were also derived from the estimated model parameters and spatially interpolated to produce maps. These maps can be used to better understand the rainfall characteristics of the continental United States.

\section{MODIFIED BARTLETT-LEWIS RECTANGULAR PULSE (MBLRP) MODEL}

In the MBLRP model, rainfall time series are represented as sequences of storms comprised of rain cells (see Fig. 1). In the model, $X_{1}[T]$ is a random variable that represents the storm arrival time, which is governed by a Poisson process with parameter $\lambda[1 / \mathrm{T}] ; \mathrm{X}_{2}[\mathrm{~T}]$ is a random variable that represents the duration of storm activity (i.e., the time window after the beginning of the storm within which rain cells can arrive), which varies according to an exponential distribution with parameter $\gamma[1 / \mathrm{T}] ; \mathrm{X}_{3}[\mathrm{~T}]$ is a random variable that represents the rain cell arrival time within the duration of storm activity, which is governed by a Poisson process with parameter $\beta[1 / \mathrm{T}] ; \mathrm{X}_{4}[\mathrm{~T}]$ is a random variable that represents the duration of the rain cells. The distribution of the rain cell durations are known to have a long-tailed distribution (Rodriguez-Iturbe et. al. 1987), which was assumed to vary according to an exponential distribution with parameter $\eta[1 / \mathrm{T}]$ that, in turn, is a random variable represented by a gamma distribution with parameters $v[\mathrm{~T}]$ and $\alpha$ [dimensionless]; and $\mathrm{X}_{5}[\mathrm{~L} / \mathrm{T}]$ is a random variable that represents the rain cell intensity, which varies according to an exponential distribution with parameter $1 / \mu[\mathrm{T} / \mathrm{L}]$. From the physical viewpoint, $\lambda$ is the expected number of storms that arrive in a given period, $1 / \gamma$ is the expected duration of storm activity, $\beta$ is the expected number of rain cells that arrive within the duration of storm activity, $1 / \eta$ is the expected duration of rain cells and $\mu$ is the average rain cell intensity. Parameters $v$ and $\alpha$ do not have a clear physical meaning, but the expected value and variance of $\eta$ can be expressed as $\alpha / v$ and $\alpha / v^{2}$. Therefore, the model has six parameters: $\lambda$, $\gamma, \beta, \nu, \alpha$ and $\mu$; however, it is customary to use the dimensionless ratios $\phi=\gamma / \eta$ and $\kappa=\beta / \eta$ as parameters instead of $\gamma$ and $\beta$.

Model parameter estimation is accomplished by matching - or minimizing the discrepancy between - statistics of the simulated and observed rainfall time series. Some commonly used statistics are the precipitation depth mean, variance, probability of zero rainfall and lag-s covariance at various time scales (Khaliq and Cunnane 1996). According to Rodriguez-Iturbe et al. (1988) and Bo et al. (1994), the statistics of the synthetically generated rainfall time series at an accumulation interval $\mathrm{T}$ are:

$$
\mathrm{E}\left[\mathrm{Y}_{\mathrm{t}}^{(\mathrm{T})}\right]=\lambda \mu \mu_{\mathrm{c}} \frac{\nu}{\alpha-1} \mathrm{~T}
$$

$$
\begin{aligned}
& \operatorname{Var}\left[\mathrm{Y}_{\mathrm{t}}^{(\mathrm{T})}\right]=\frac{2 \mathrm{v}^{2-\alpha} \mathrm{T}}{\alpha-2}\left(\mathrm{k}_{1}-\frac{\mathrm{k}_{2}}{\phi}\right)-\frac{2 \mathrm{v}^{3-\alpha}}{(\alpha-2)(\alpha-3)}\left(\mathrm{k}_{1}-\frac{\mathrm{k}_{2}}{\phi}\right) \\
& +\frac{2}{(\alpha-2)(\alpha-3)}\left[\mathrm{k}_{1}(\mathrm{~T}+\nu)^{3-\alpha}-\frac{\mathrm{k}_{2}}{\phi^{2}}(\phi \mathrm{T}+\nu)^{3-\alpha}\right]
\end{aligned}
$$




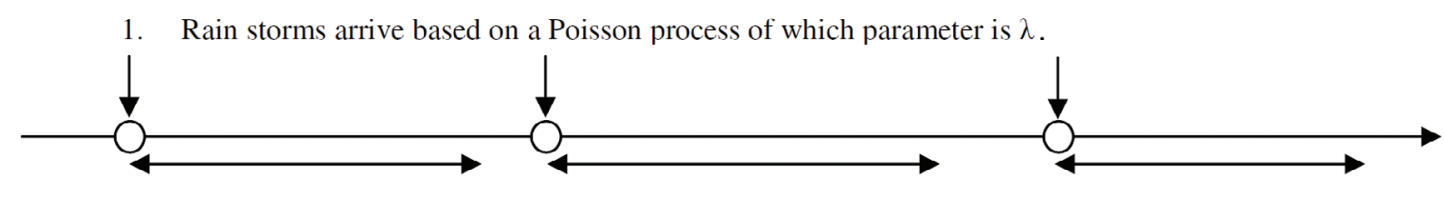

2. Duration of storm activity is determined by an exponential distribution with parameter $\gamma$.

3. Rain cells arrive based on a Poisson process with parameter $\beta$.
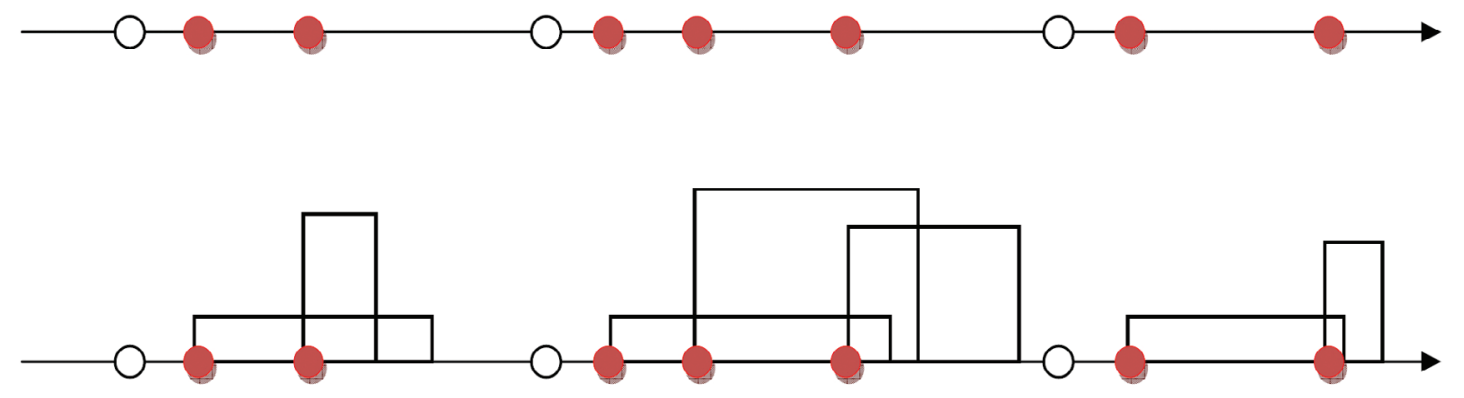

4. Each rain cell is assigned with random duration and intensity. Duration is randomly drawn from an exponential distribution with parameter $\eta$, and intensity is randomly drawn from another exponential distribution with parameter $1 / \mu$. Here, the parameter $\eta$ is randomized again for each rain storm by Gamma distribution with parameter $v[\mathrm{~T}]$ and $\alpha$.

Fig. 1. Schematic of the MBLRP model. White and gray circles represent the arrival time of storms and rain cells, respectively. Each rain cell is represented by a rectangle whose width and height represent its duration and rainfall intensity.

$$
\begin{aligned}
& \operatorname{Cov}\left[\mathrm{Y}_{\mathrm{t}}^{(\mathrm{T})}, \mathrm{Y}_{\mathrm{t}+\mathrm{s}}^{(\mathrm{T})}\right]=\frac{\mathrm{k}_{1}}{(\alpha-2)(\alpha-3)}\left\{[\mathrm{T}(\mathrm{s}-1)+v]^{3-\alpha}\right. \\
& \left.+[\mathrm{T}(\mathrm{s}+1)+v]^{3-\alpha}-2(\mathrm{Ts}+\nu)^{3-\alpha}\right\}+\frac{\mathrm{k}_{2}}{\phi^{2}(\alpha-2)(\alpha-3)} \\
& \cdot\left\{2(\phi \mathrm{Ts}+v)^{3-\alpha}-[\phi \mathrm{T}(\mathrm{s}-1)+v]^{3-\alpha}-[\phi \mathrm{T}(\mathrm{s}+1)+v]^{3-\alpha}\right\}
\end{aligned}
$$

$$
\mathrm{P}(\text { zero rainfall })=\exp \left\{-\lambda \mathrm{T}-\frac{\lambda \nu}{\phi(\alpha-1)}[1+\phi(\kappa+\phi)\right.
$$$$
\left.-\frac{1}{4} \phi(\kappa+\phi)(\kappa+4 \phi)+\frac{\phi(\kappa+\phi)\left(4 \kappa^{2}+27 \kappa \phi+72 \phi^{2}\right)}{72}\right]+
$$$$
\frac{\lambda v}{(\alpha-1)(\kappa+4 \phi)}\left(1-\kappa-\phi+\frac{3}{2} \kappa \phi+\phi^{2}+\frac{\kappa^{2}}{2}\right)+\frac{\lambda v}{(\alpha-1)(\kappa+\phi)}
$$$$
\left.\cdot\left[\frac{v}{v+(\kappa+\phi) \mathrm{T}}\right]^{\alpha-1} \frac{\kappa}{\phi}\left(1-\kappa-\phi+\frac{3}{2} \kappa \phi+\phi^{2}+\frac{\kappa^{2}}{2}\right)\right\}
$$

where

$$
\begin{aligned}
& \mathrm{k}_{1}=\left(2 \lambda \mu_{\mathrm{c}} \mu^{2}+\frac{\lambda \mu_{\mathrm{c}} \kappa \phi \mu^{2}}{\phi^{2}-1}\right)\left(\frac{\nu^{\alpha}}{\alpha-1}\right) \\
& \mathrm{k}_{2}=\left(\frac{\lambda \mu_{\mathrm{c}} \kappa \phi \mu^{2}}{\phi^{2}-1}\right)\left(\frac{\nu^{\alpha}}{\alpha-1}\right) \\
& \mu_{\mathrm{c}}=1+\frac{\kappa}{\phi}
\end{aligned}
$$

$\mathrm{S}$ is the lag time in number of accumulation intervals, and $\mathrm{Y}_{\mathrm{t}}^{(\mathrm{T})}$ is the rainfall time series at an accumulation interval T.

\section{DEVELOPMENT OF THE MBLRP MODEL PA- RAMETER MAPS}

As of 2006, there were 6356 hourly rain gauges in the contiguous United States, 3444 of which had a period of record longer than 20 years (NCDC 2011a, b) (see Fig. 2). These gauges were used for model calibration and validation. Model parameters at each rain gauge for each month were determined such that the difference between the statistics of the simulated and observed rainfall time series was minimized. Once the parameters were determined at each rain gauge, they were spatially interpolated using the Ordinary Kriging technique to generate maps from which parameter values for any point could be obtained.

\subsection{Rain Gauge Statistics}

For each of the 3444 gauges and month of the year (i.e., January, February, March, ...), the precipitation depth mean, variance and lag-1 autocorrelation coefficient and the probability of zero rainfall were calculated at 1-, 3-, 12- and 24-hour accumulation levels. The means at 3-, 12-, and 24- 


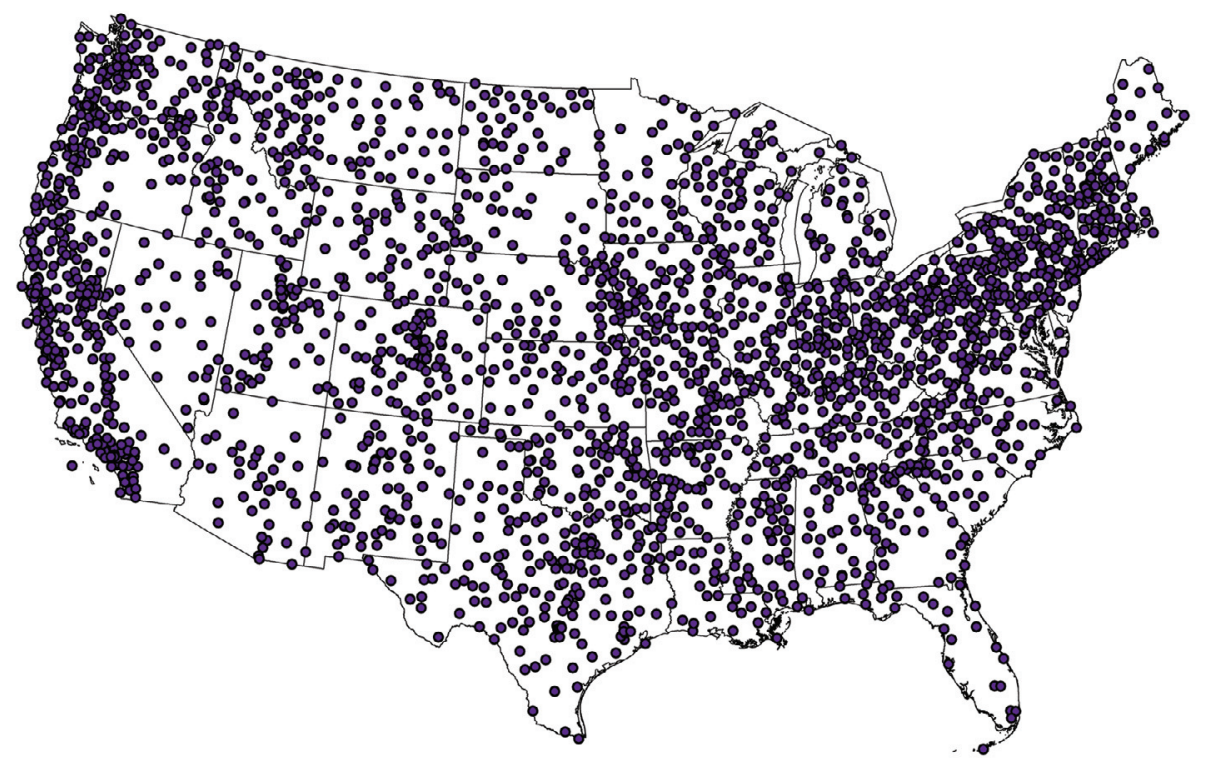

Fig. 2. Location of the 3444 NCDC rain gauges with hourly recording and period of record longer than 20 years.

hour accumulation levels were not calculated because those will be the same as the one calculated at 1-hour accumulation level. As a result, a total of 13 statistics per month (note that the mean is not affected by the accumulation level) was obtained. Different accumulation intervals and months were considered to capture the sub-daily and seasonal precipitation variability. As a reference, maps of the four statistics for an accumulation interval of one hour for the month of May are shown in Fig. 3. Higher-order moments of the precipitation depth were not included in this study because, even though they help represent better the tails of the precipitation distribution (Cowpertwait 1998), the successful modeling of extreme rainfall values at different accumulation intervals is still a pending matter and beyond the scope of this study (Kim et al. 2013). The Ordinary Kriging interpolation technique was used to generate maps that adopted the spherical shape of variogram. The parameters of the variograms were determined such that they minimize the sum of the square of the residuals between the model and sample variogram. For all months and accumulation intervals, the mean, variance and probability of zero rainfall showed a strong regional tendency. The regional tendency of the lag1 autocorrelation was not as strong as that of the other three statistics. Detailed discussion on the weak regional tendency of the lag-1 autocorrelation and its effect on the parameter regionalization are presented later in this article.

\subsection{Objective Function}

Because it is not possible to analytically solve Eqs. (1) through (4) for the MBLRP model parameters of each rain gauge and month (Onof et al. 2000), the parameters were obtained by minimizing the following objective function
OF, which represents the discrepancy between the statistics of the observed and simulated rainfall time series:

$\mathrm{OF}=\sum_{\mathrm{k}=1}^{\mathrm{n}} \mathrm{w}^{\mathrm{k}}\left[1-\frac{\mathrm{F}_{\mathrm{k}}(\vec{\theta})}{\mathrm{f}_{\mathrm{k}}}\right]$

where $\vec{\theta}$ is the parameter vector $(\lambda, v, \alpha, \mu, \phi, \kappa), \mathrm{n}$ is the number of statistics being matched, $\mathrm{F}_{\mathrm{k}}(\vec{\theta})$ is the $\mathrm{k}^{\text {th }}$ statistic of the simulated rainfall time series, $\mathrm{f}_{\mathrm{k}}$ is the $\mathrm{k}^{\text {th }}$ statistics of the observed rainfall time series. Note that, in Eq. (5), all statistics have been given the same weight $-\mathrm{w}^{\mathrm{k}}$ in Eq. (5), despite not all of them having the same relative importance, and that the parameters determined with it will reflect this assumption. Kim and Olivera (2012) discussed an approach to estimate weight factors for the different statistics in Eq. (5) and indicate they should depend on the specific application. The statistics used in the model calibration were the same 13 statistics calculated for the gauges (i.e., $\mathrm{n}=13$ ). According to Khaliq and Cunnane (1996), models calibrated based on these statistics at various accumulation levels produce rainfall time series that resemble historical observations. Higher-order moments were not included in the objective function despite the fact that matching them would have helped capture better low-frequency events (Cowpertwait 1998); however, at the expense of losing accuracy for higher-frequency events.

\subsection{Multi-Modality of the Objective Function}

In order to generate rainfall time series at any given point, parameter maps were obtained by interpolating the parameter values estimated for the rain gauges. Obtaining 
(a)

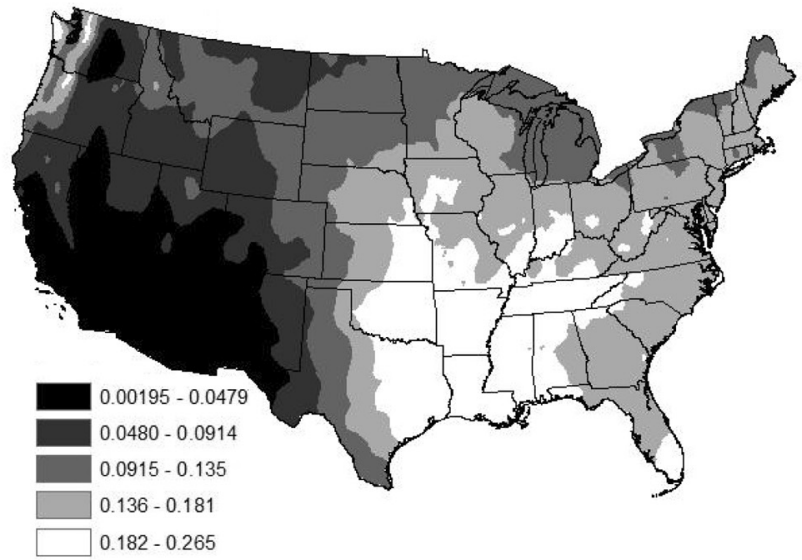

(c)

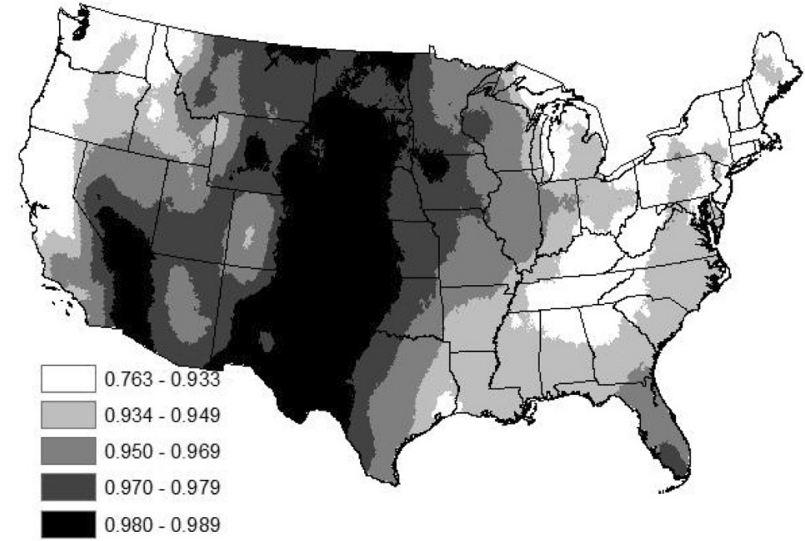

(b)

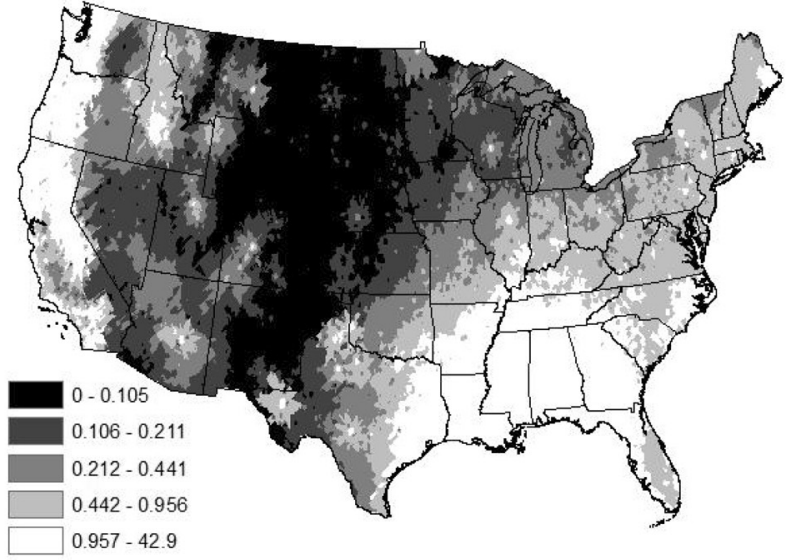

(d)

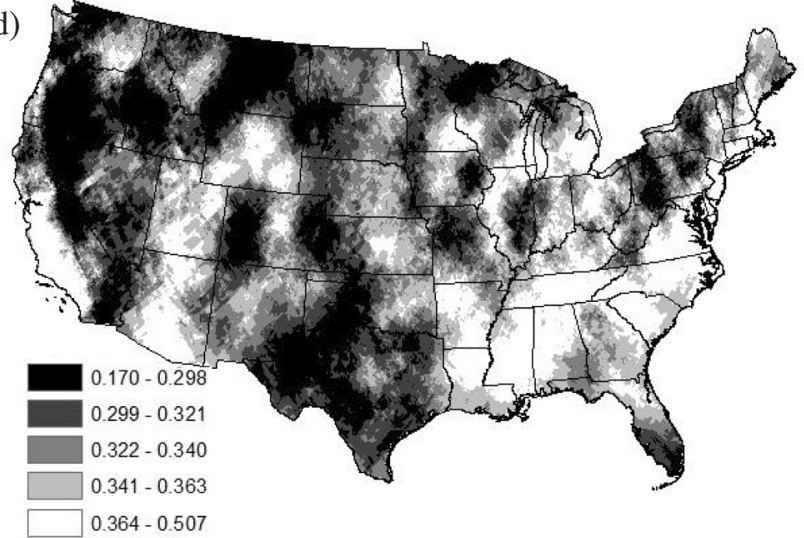

Fig. 3. Rainfall statistics for one hour accumulation interval for the month of May. From top to bottom and left to right, (a) mean (mm hr $\left.{ }^{-1}\right)$, (b) variance $\left(\mathrm{mm}^{2} \mathrm{hr}^{-2}\right)$, (c) probability of zero rainfall, and (d) lag-1 autocorrelation coefficient.

reliable results from this interpolation, however, is not straightforward because of the multi-modality of the objective function. What the multi-modality of the objective function is in this problem is presented with an example hereinafter. Let rain gauges A and B be located close to each other. Despite the gauges being located at different locations, for the sake of simplicity, it is assumed that both are affected identically by the storm depicted in Fig. 4. In the figure, the storm at gauge $\mathrm{A}$ is represented by two rain cells while the one at gauge $B$ by six rain cells, where the rain cells at $\mathrm{A}$ have longer duration and greater rainfall depth than those at B, but the overall result is the same. That is, a storm - or a precipitation time series if we refer to a longer period - can be represented by different parameter vectors. The existence of different and equally-correct solutions for the parameter vector is represented as multiple minima of the objective function in the parameter space and referred to as multi-modality (Gyasi-Agyei 1999; Onof et al. 2000). Because of this multi-modality, spatial interpolation of the parameter values between gauges A and B might yield incorrect estimates.

To address this multi-modality problem, as many minima as possible of the objective function were identified at each gauge, and one of them was assumed to be the correct parameter vector. The Isolated Speciation-Based Particle Swarm Optimization (ISPSO) method (Cho et al. 2011) was used to identify the parameter vectors that generated minima within a given parameter space. The range of the parameters within which the parameters were estimated is provided in Table 1. The ISPSO assumes that it has found a solution when a best local particle converges to a point in the search space such that the particle's age - the number of iterations during which the particle survived without being killed - is older than 10, and the normalized geometric mean of the particle's past half-life trajectory is smaller than 0.00001, and the standard deviation of the particle's past half-life fitness values is smaller than 0.0001 . The swarm size is 14 and 500 iterations were performed; for a total of 7000 function evaluations were performed.

The following procedure was followed to select the correct parameter vector. A gauge in which the global minimum is clearly lower than the other minima was chosen as an anchor gauge for estimating the parameter vectors in other gauges. The parameter vector that generates that global minimum was taken as the correct one at the gauge. In this specific study, the identical anchor gauge was used for all 


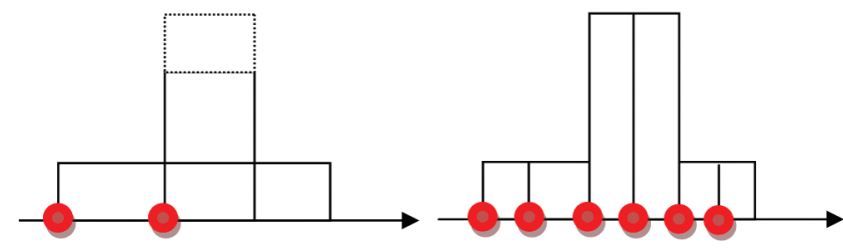

Fig. 4. Rainfall event modeled with two different parameter sets.

Table 1. Parameter range for model calibration.

\begin{tabular}{l|cc|cc}
\hline \multirow{2}{*}{ Parameters } & \multicolumn{2}{|c|}{$\begin{array}{c}\text { Parameter Range } \\
\text { (Original) }\end{array}$} & \multicolumn{2}{c}{$\begin{array}{c}\text { Parameter Range } \\
\text { (After Cross-Validation) }\end{array}$} \\
\cline { 2 - 5 } & Minimum & Maximum & Minimum & Maximum \\
\hline$\lambda\left(1 \mathrm{hr}^{-1}\right)$ & 0.000010 & 0.045 & 0.00001 & 0.025 \\
$\nu(\mathrm{hr})$ & 2.0 & 10 & 5.5 & 8.8 \\
$\alpha$ & 6 & 300 & 20 & 140 \\
$\mu\left(\mathrm{mm} \mathrm{hr}^{-1}\right)$ & 0.83 & 150 & 1 & 40 \\
$\phi$ & 0.0013 & 0.40 & 0.01 & 0.06 \\
$\kappa$ & 0.01 & 0.99 & 0.03 & 0.44 \\
\hline
\end{tabular}

months, which is the gauge located at Sawtooth National Forest in the State of Idaho (Latitude: 43.3586, Longitude: -115.4458). To select the parameter vector at a neighboring gauge that best captures the regional tendency, normalized Euclidean distances in the six-dimensional parameter space between the anchor gauge parameter vector and the many parameter vectors of the new gauge are calculated. The parameter vector of the new gauge with the lowest normalized Euclidean distance was taken as the correct parameter vector. Mathematically, let $\overrightarrow{\mathrm{A}_{1}}$ be the already-determined parameter vector at gauge $\mathrm{A}$, and let $\overrightarrow{\mathrm{B}_{1}}, \overrightarrow{\mathrm{B}_{2}}, \ldots \overrightarrow{\mathrm{B}_{\mathrm{n}}}$ be the estimated parameter vectors at neighboring gauge $\mathrm{B}$, each of which is associated with a local minimum. The normalized Euclidean distance $\Delta$ between parameter vectors $\overrightarrow{\mathrm{A}_{1}}$ and $\overrightarrow{\mathrm{B}_{\mathrm{j}}}$ is defined as follows:

$\Delta_{\mathrm{j}}=\sqrt{\sum_{\mathrm{i}=1}^{6}\left[\frac{\mathrm{P}_{\mathrm{i}}^{\mathrm{A}}-\mathrm{P}_{\mathrm{ij}}^{\mathrm{B}}}{\max \left(\mathrm{P}_{\mathrm{i}}\right)-\min \left(\mathrm{P}_{\mathrm{i}}\right)}\right]^{2}}$

where $\mathrm{P}_{\mathrm{i}}^{\mathrm{A}}$ represents the $\mathrm{i}^{\text {th }}$ parameter at gauge $\mathrm{A}, \mathrm{P}_{\mathrm{ij}}^{\mathrm{B}}$ represents $\mathrm{i}^{\text {th }}$ parameter of the $\mathrm{j}^{\text {th }}$ parameter vector at gauge $\mathrm{B}$, and $\max \left(\mathrm{P}_{\mathrm{i}}\right)$ and $\min \left(\mathrm{P}_{\mathrm{i}}\right)$ represent the maximum and minimum values of parameter $\mathrm{P}_{\mathrm{i}}$ estimated at all gauges, respectively. The parameter vector $\overrightarrow{\mathrm{B}}_{\mathrm{j}}$ with the lowest normalized Euclidean distance is selected as the correct parameter vector at gauge B. The procedure continues one gauge at a time targeting the gauges that are closest to the ones at which the correct parameter vectors have already been determined. By applying this methodology, the variability between the parameter values in neighboring gauges is reduced because they tend to correspond to values that represent equivalent descriptions of the rainfall patterns (i.e., comparable number of rain cells with comparable rain cell durations).

\subsection{Spatial Interpolation of the Parameter Values}

After the correct parameter vectors were estimated at each of the 3444 rain gauges, the Ordinary Kriging interpolation method (Journel and Huijbregts 1978) was applied to obtain surface maps of each parameter and month. In this interpolation the parameter value and rain gauge locations were taken into account. Ordinary Kriging was used because an unknown constant spatial trend of the parameter values being interpolated was assumed. Other interpolation methods, such as Simple or Universal Kriging, require knowing the constant or variable spatial trend of the data, respectively, and could not be used. A total of 72 monthly parameter maps (i.e., 6 parameters $\times 12$ months) were generated. The variograms used in the interpolation of the model parameters were assumed to have a spherical shape and their properties were determined such that they minimize the sum of the square of the residuals between the model and sample variogram. The reader is referred to Journel and Huijbregts (1978) for detailed discussion of the Kriging interpolation method.

\section{DISCUSSION}

As observed by Islam et al. (1990), the sensitivity of each rainfall statistic to each parameter is different. Specifically, they indicate that the lag- 1 autocorrelation coefficient is strongly sensitive to $\kappa, \nu$, and $\alpha$, and insensitive to $\lambda, \mu$ and $\phi$; while the probability of zero rainfall is strongly sensitive to $\lambda$, somewhat sensitive to $v, \alpha$ and $\phi$, and insensitive to $\mu$. In fact, statistics sensitive to parameters with strong regional and/or seasonal patterns also tend to show strong regional and/or seasonal variability, and vice versa.

\subsection{Cross Validation of the Estimated Parameter Values}

Cross-validation was used to determine the robustness of the parameter interpolation. In cross-validation, parameter values at the gauges were compared to the values that would have been obtained by spatial interpolation of the parameter values of neighboring gauges. If the approach presented above were robust the calculated and interpolated values would be very similar or, ideally, equal. As a reference, Fig. 5 illustrates the results of cross-validating the six parameters for the month of May. The regression equation and the $\mathrm{R}^{2}$ values for each plot is given in Table 2 . The parameter space for the ISPSO runs was determined, as a first approximation, based on the results of Bo et al. (1994) and was redefined iteratively afterwards based on cross-validation results. Table 1 shows the original parameter range 
and the one that was narrowed after the cross-validation. Plots of other months show similar patterns. In these plots, if the estimated parameter values and those calculated by interpolation were equal, the points in the graph would coincide with the 1:1 line. Note that significant variability of the parameter values among neighboring gauges affects the reliability of the parameter interpolation in the area.

\subsection{Regional and Seasonal Patterns of the Model Pa- rameters}

In the monthly statistic maps (four of which are shown in Fig. 3), the mean, variance and probability of zero rainfall show clear regional patterns, while the lag-1 autocorrelation coefficient not to the same extent. Consequently, $\lambda$ is expected to show a strong regional variability, while $\kappa, v$, and $\alpha$ are not necessarily.

In Fig. 5, note a stronger concentration of points around the $1: 1$ line for $\lambda$ and $\mu$ than for $\phi, \kappa, v$, and $\alpha$. Correlation coefficients between the estimated and cross-validated parameters are 0.81 and 0.63 for $\lambda$ and $\mu$, respectively, which could be interpreted as an indicator of a strong spatial pattern; while, for $\phi, \kappa, v$ and $\alpha$, the correlation coefficients are $0.43,0.52,0.11$ and 0.40 , respectively, indicating a much
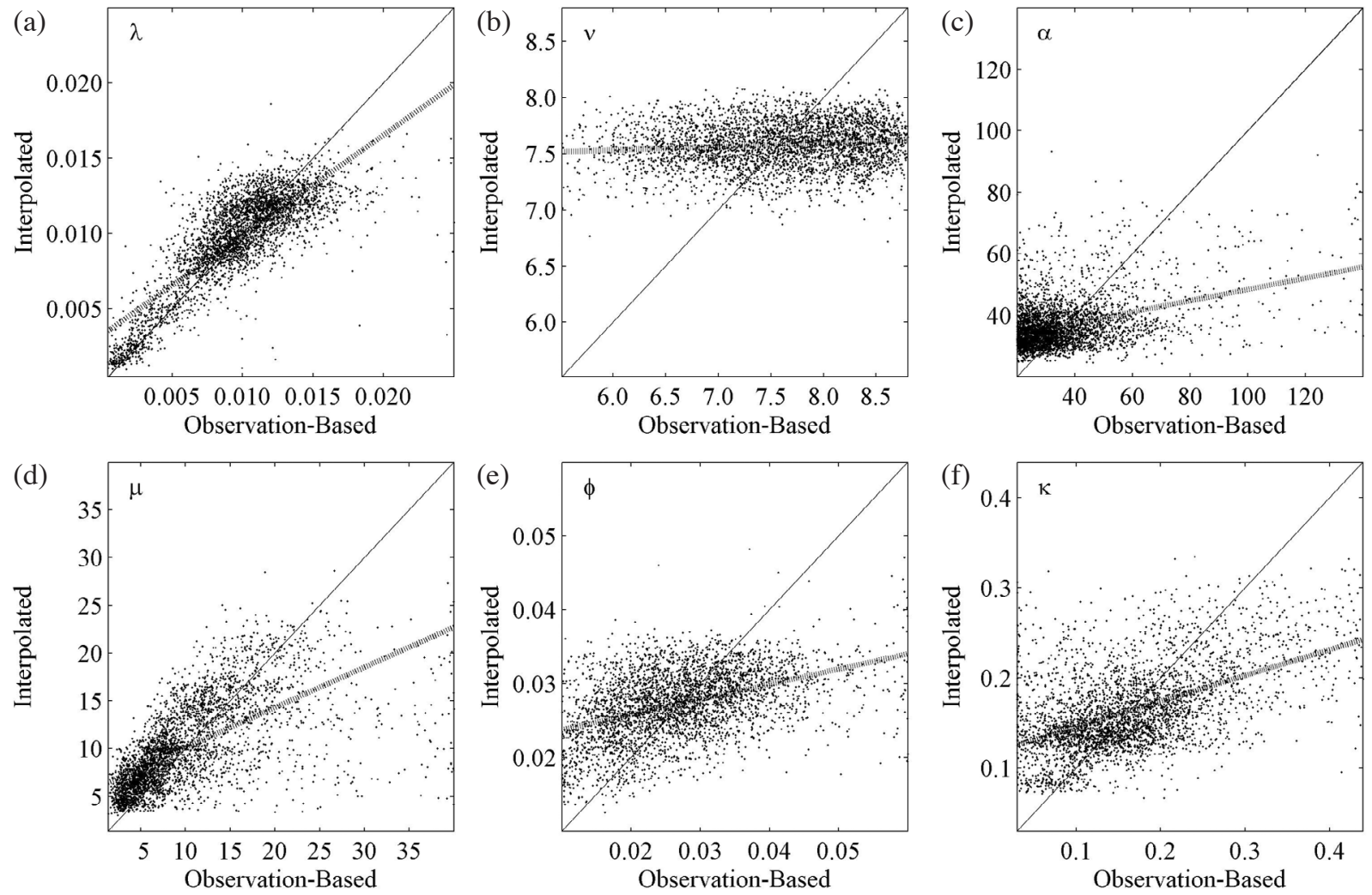

Fig. 5. Results of cross-validation of the parameters for the month of May. Parameter values estimated by optimization are shown on the $\mathrm{x}$-axis and by cross-validation (interpolation of neighboring gauges) on the y-axis. From the top to bottom and left to right, $\lambda\left(1 \mathrm{hr} r^{-1}\right), v(\mathrm{hr}), \alpha, \mu\left(\mathrm{mm} \mathrm{hr}{ }^{-1}\right), \phi$ and $\kappa$.

Table 2. Regression equation between the estimated and cross-validated parameters and the corresponding $\mathrm{R}^{2}$ values.

\begin{tabular}{|c|c|c|c|c|}
\hline \multirow{2}{*}{ Parameters } & \multicolumn{2}{|c|}{ Original Parameter Range } & \multicolumn{2}{|c|}{ Parameter Range after Cross-Validation } \\
\hline & Equation & $\mathbf{R}^{2}$ & Equation & $\mathbf{R}^{2}$ \\
\hline$\lambda\left(1 \mathrm{hr}^{-1}\right)$ & $Y=0.572 X+0.0043$ & 0.54 & $Y=0.664 X+0.0032$ & 0.66 \\
\hline$v(\mathrm{hr})$ & $Y=0.00001 X+7.3981$ & $3 \times 10^{-7}$ & $Y=0.0311 X+7.35$ & 0.012 \\
\hline$\alpha$ & $Y=0.136 X+42.76$ & 0.083 & $Y=0.421 X+5.91$ & 0.16 \\
\hline$\mu\left(\mathrm{mm} \mathrm{hr}^{-1}\right)$ & $Y=0.154 X+10.53$ & 0.091 & $Y=0.205 X+0.0217$ & 0.40 \\
\hline$\phi$ & $Y=0.144 X+0.0252$ & 0.093 & $\mathrm{Y}=0.205 \mathrm{X}+0.0217$ & 0.19 \\
\hline$\kappa$ & $Y=0.159 X+0.147$ & 0.11 & $Y=0.2857 X+0.117$ & 0.27 \\
\hline
\end{tabular}


weaker one. Likewise, student t-tests were performed on the slope of the regression lines with the null hypotheses that they were equal to zero; that is, the null hypotheses implied that the parameter values at a gauge are not related to those of their neighbor gauges and that no spatial pattern existed. The $\mathrm{t}$-values for the parameter $\lambda, v, \alpha, \mu, \phi$, and $\kappa$ were $81.5,6.69,25.3,47.8,27.9$, and 78.7 , respectively. These values correspond to the p-values that lead to the rejection of the null hypotheses with a $99 \%$ of significance, implying that all slopes were statistically different from zero. In other words, the value of all parameters at a given location can be predicted, to some extent, by the value of the parameters at its neighboring gauges.

Figure 6 shows maps of interpolated parameter values for the month of May. Confirming what was observed above, a spatial pattern is clearer for $\lambda$ and $\mu$ than for the
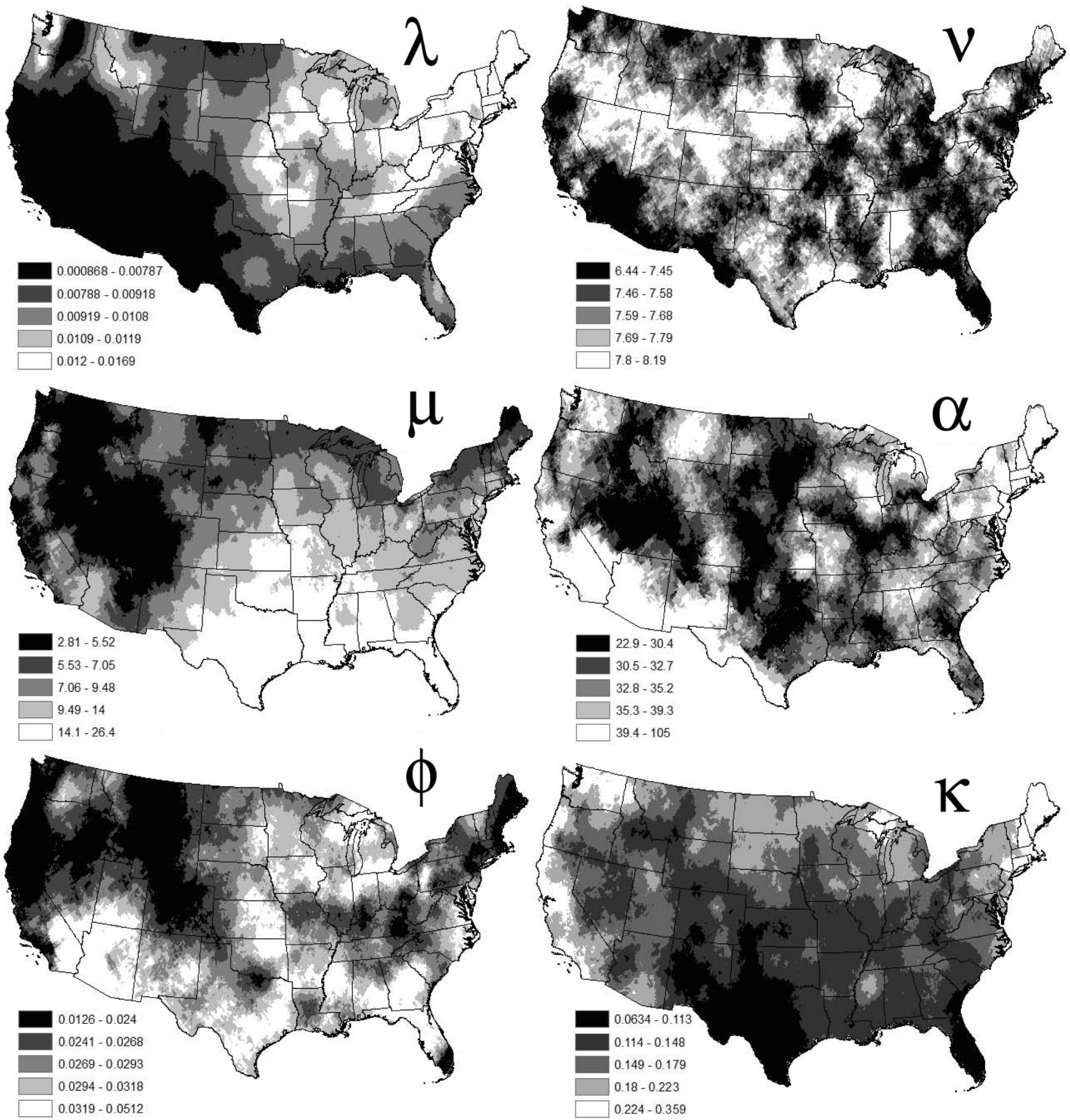

Fig. 6. MBLRP model parameters for the month of May. From the top to bottom and left to right, $\lambda\left(1 \mathrm{hr}^{-1}\right), v(\mathrm{hr}), \mu\left(\mathrm{mm} \mathrm{hr} r^{-1}\right), \alpha, \phi$ and $\kappa$. The maps in digital format are downloadable at the $1^{\text {st }}$ author's website http://huniv.hongik.ac.kr/ dekaykim/MBLRP USA/MBLRP USA.zip. 
other parameters; however, based on the maps, $\phi$ and $\kappa$ also show discernible spatial patterns, particularly if the number of rain gauges included in the analysis is considered. Note that parameter $\lambda$, because it is associated to an observable physical variable such as the number of storms per unit time, is less inclined to be affected by the multi-modality of the model calibration. Comparison of our map of $\lambda$ for the month of May with that of Hawk and Eagleson (1992) shows similar regional patterns in both maps, with low and high values in very much the same areas. Although not identical, the maps greatly resemble each other, even though differences can be identified. Our map, for instance, is more complex in its shapes, most likely, because of the significantly larger number of rain gauges used to develop it. The range of $\lambda$ values is 0.00089 to 0.017 storms per hour in our map and 0.001 (value extrapolated) to 0.019 storms per hour in theirs. The comparison of the maps of $\lambda$ for the other months was similar and is not included here because of space limitations. Maps of the other parameters were not compared because their values were affected by the multimodality of the objective function used to calculate them, and should be taken as a set and not individually.

Figure 7 shows the seasonal variability of the pa- rameters and rainfall statistics of two randomly-selected gauges in the states of New York (NCDC 3851 located at $75.5208^{\circ} \mathrm{W}, 43.5753^{\circ} \mathrm{N}$ ) and Washington (NCDC 6858 located at $\left.124.5550^{\circ} \mathrm{W}, 47.9375^{\circ} \mathrm{N}\right)$. In the figure, it can be seen that seasonality is not apparent in gauge NCDC 3851, while it is reflected in the parameter $\lambda$ and the statistics of NCDC 6858 . Based on the temporal variability of the parameter values and statistics in a large number of rain gauges, it was observed that seasonality of some of the parameters depended on the seasonality of the statistics. In general, $\lambda$ showed the strongest seasonal variability because the parameter $\lambda$ is highly influenced by the rainfall mean, which shows strongest seasonal variability. For the same reason, parameter $v$ showed the weakest seasonal variation because it is highly influenced by the lag- 1 autocorrelation of rainfall, which does not have clear seasonal tendency.

\subsection{Rainfall Characteristics Based on the Model Param- eter Values}

Rainfall characteristics, such as the average rainfall depth per storm, the average storm duration, the average number of rain cells per storm, the average rain cell arrival
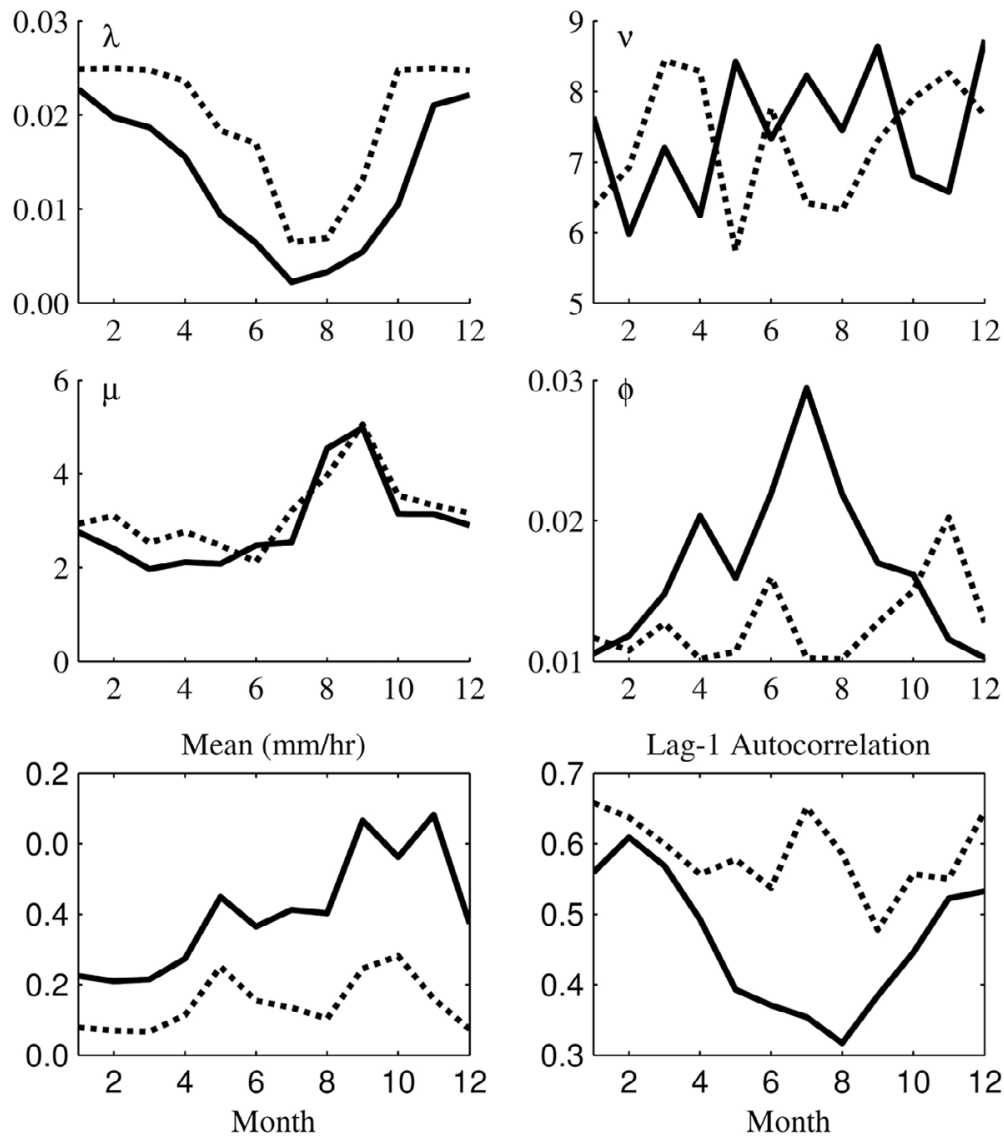
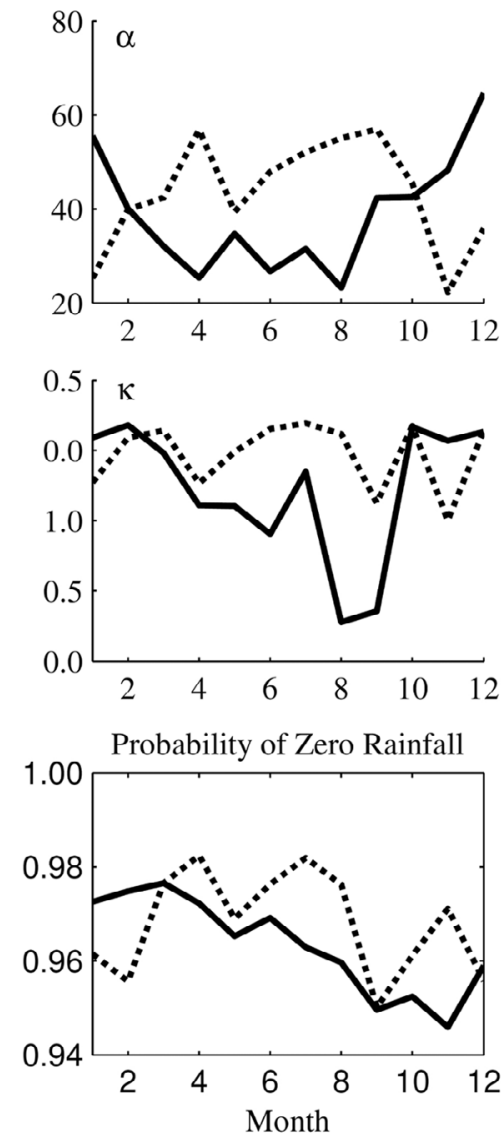

Fig. 7. Monthly variation of the parameters and statistics of gauges NCDC 3851 (black line) located at $75.5208^{\circ} \mathrm{W}, 43.5753^{\circ} \mathrm{N}$ in the state of New York, and NCDC 6858 (gray line) located at $124.555^{\circ} \mathrm{W}, 47.9375^{\circ} \mathrm{N}$ in the state of Washington. 
rate or the average rain cell duration can be estimated based on the MBLRP parameters. According to Hawk and Eagleson (1992), these rainfall characteristics can be expressed as:

Average rainfall depth per storm $[\mathrm{L}]=\mu \frac{\mathcal{V}}{\alpha}\left(1+\frac{\kappa}{\phi}\right)$

Average duration of storm activity $[\mathrm{T}]=\frac{\nu}{\phi \alpha}$

Average number of rain cells per storm $=1+\frac{\kappa}{\phi}$
Average rain cell arrival rate $[1 / \mathrm{T}]=\frac{\kappa \alpha}{\nu}$

Average rain cell duration $[\mathrm{T}]=\frac{\nu}{\alpha}$

These rainfall characteristics were calculated at all gauges and interpolated with the Ordinary Kriging technique. Figure 8 illustrates these interpolated surfaces for the month of May. Other storm and rain cell characteristics such as the average number of storms arriving during a given
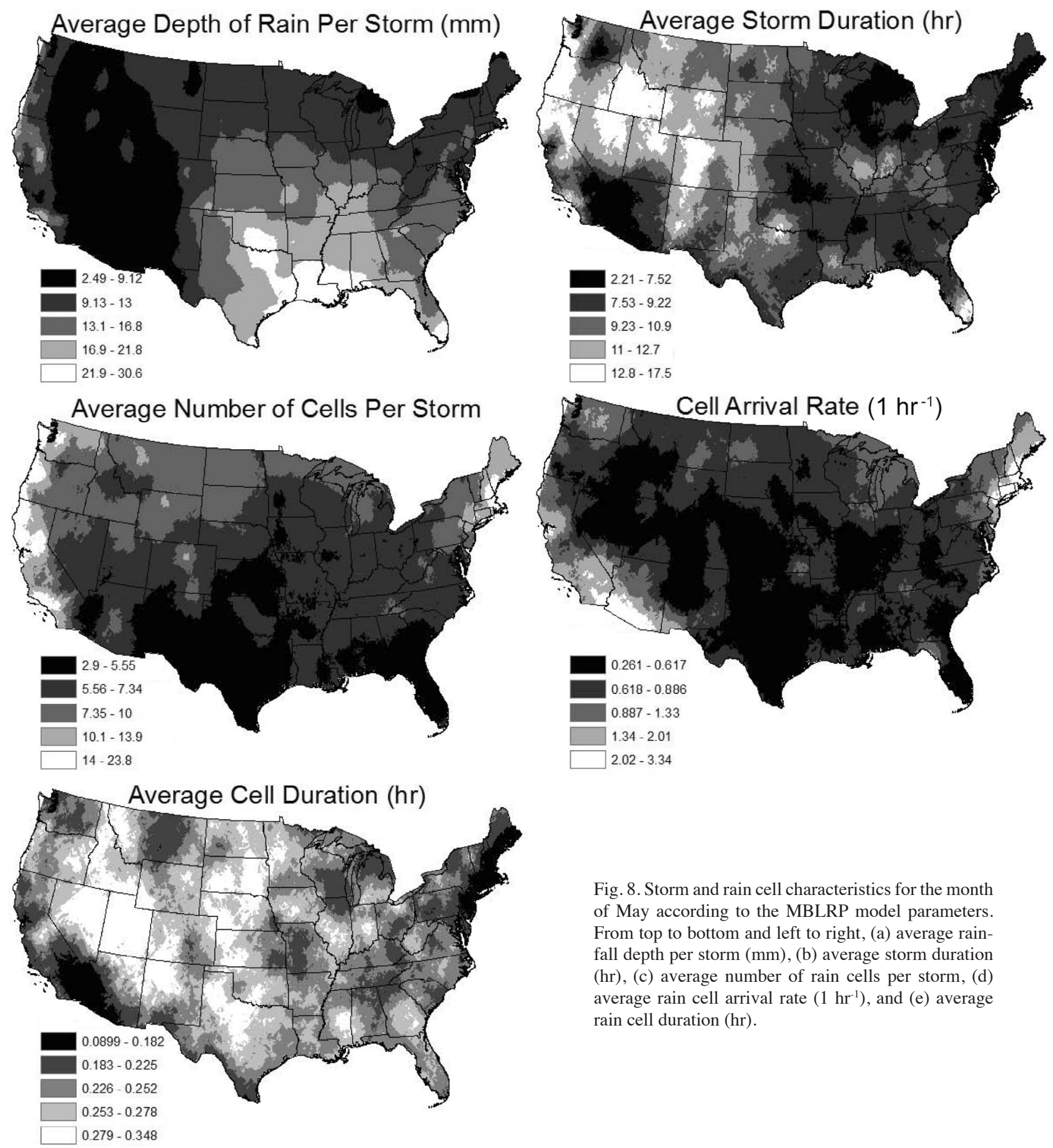

Fig. 8. Storm and rain cell characteristics for the month of May according to the MBLRP model parameters. From top to bottom and left to right, (a) average rainfall depth per storm (mm), (b) average storm duration (hr), (c) average number of rain cells per storm, (d) average rain cell arrival rate $\left(1 \mathrm{hr}^{-1}\right)$, and (e) average rain cell duration (hr). 
period $(\lambda)$ and average precipitation rate of each rain cell $(\mu)$ were already presented in Fig. 6 . As a reference Table 3 compares the rainfall characteristic for the month of May at four locations of the United States with the same mean monthly rainfall $(141 \mathrm{~mm})$. It was observed that the rainfall depth per storm, which is an observable physical variable and, therefore, less affected by the multi-modality of the model calibration, showed a strong regional pattern. The other storm and rain cell characteristics showed less well defined spatial patterns, most likely because an error in any of them can be compensated by an error in other.

\subsection{Validation of the Parameter Maps}

Validation of the parameter maps consisted of comparing the statistics of the observed rainfall and of the simulated rainfall obtained using the cross-validated parameter sets. Cross-validated parameter values were used because they have the level of accuracy of the parameters estimated by interpolation at points where no gauges are located. The statistics used for validation were precipitation depth mean, variance and lag-1 autocorrelation coefficient, and probability of zero rainfall for accumulation intervals of $1,3,6$, 12 and 24 hours (note that the 6-hour accumulation interval was not used in calibration). This comparison was performed for all 3444 NCDC hourly precipitation gauges used to generate the maps. The results for the month of May are shown in Fig. 9. In the figure the dotted lines correspond to the 95\% prediction interval of the regression line. The width of the range represents the uncertainty in the statistics of the simulated rainfall. Qualitatively speaking the predictions can be considered satisfactory for the mean, variance and probability of zero rainfall for different levels of accumulation, but not to the same extent for the lag-1 autocorrelation coefficient. Note that the lag-1 autocorrelation coefficients of the simulated rainfall time series tend to vary over a much narrower range than those of the observed precipitation. Table 4 shows the mean and standard deviation of the residuals between the observed rainfall statistics and the simulated rainfall statistics produced from the cross-validated param- eter maps. The residual of all 4 types of statistics at all accumulation levels follows the normal distribution according to the k-s test, thus the quantification of the uncertainty induced in using the parameter map values is possible.

However, despite successfully reproducing most of the observed rainfall time series statistics for the great majority of rain gauges, they were not for a number of them. For an accumulation interval of one hour $5 \%$ of the gauges with the greatest residuals between each of the statistics of the observed and simulated precipitation time series showed the following characteristics: (1) for the mean, their average annual rainfall was $1650 \mathrm{~mm}$ and were located mostly along the northeast and northwest coast, although a number of them were evenly distributed east of the $100^{\circ} \mathrm{W}$ meridian; (2) for the variance, their average annual rainfall was $1750 \mathrm{~mm}$ and were located mostly evenly distributed east of the $100^{\circ} \mathrm{W}$ meridian, although a small number were located along the northwest coast; (3) for the probability of zero rainfall, their average annual rainfall was $1250 \mathrm{~mm}$ and were located in the northeast and northwest parts of the country; and (4) for the lag-1 autocorrelation coefficient, their average annual rainfall was $750 \mathrm{~mm}$ and were located mostly west of the $100^{\circ} \mathrm{W}$ meridian with a higher concentration along the coast, although a small number of them were located in the northeast. Note that the average annual precipitation in the country is $1250 \mathrm{~mm}$. Even though mismatches in all statistics were found based on the results presented in Fig. 9, the lag-1 autocorrelation coefficient was of concern. For this statistic the location of the gauges where the mismatch was more pronounced coincided in part with the driest parts of the country. Likewise, the fact that gauges in the northwest coast have some of the greatest residuals for all statistics seems to respond to high spatial variability of precipitation in the area and the limitations of the interpolation technique to capture it with the existing gauge network.

\subsection{Resolution of Multi-Modality}

The multi-modality of the objective function, as previously discussed, puts a major obstruction in obtaining the

Table 3. Average rainfall characteristics for the month of May for selected locations with mean monthly rainfall depth of $141 \mathrm{~mm}$.

\begin{tabular}{lcccc}
\hline \multicolumn{1}{c}{ State } & Texas & Iowa & Washington & Florida \\
\hline Longitude & $-95.592^{\circ}$ & $-93.591^{\circ}$ & $-123.975^{\circ}$ & $-80.913^{\circ}$ \\
Latitude & $30.349^{\circ}$ & $41.966^{\circ}$ & $47.862^{\circ}$ & $27.050^{\circ}$ \\
Rainfall depth per storm (mm) & 22.2 & 13.5 & 14.2 & 19.2 \\
Storm duration (hr) & 7.9 & 8.7 & 12.1 & 11.7 \\
Number of rain cells per storm & 4.7 & 6.0 & 16.4 & 4.0 \\
Rain cell arrival rate (1 hr-1) & 0.57 & 0.61 & 1.30 & 0.38 \\
Rain cell Duration (hr) & 0.24 & 0.28 & 0.21 & 0.24 \\
\hline
\end{tabular}



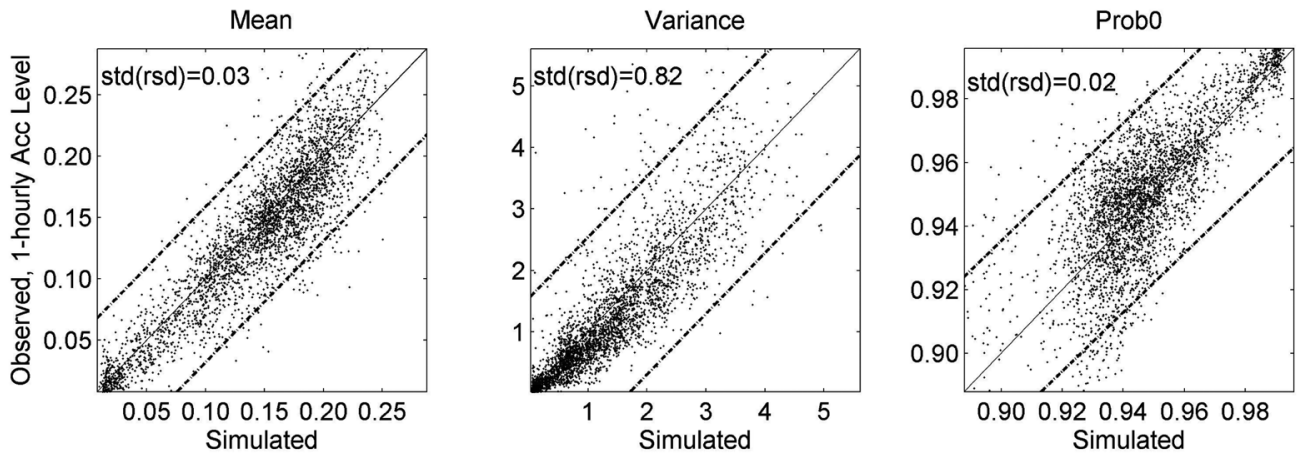

Lag-1 Auto-Correlation
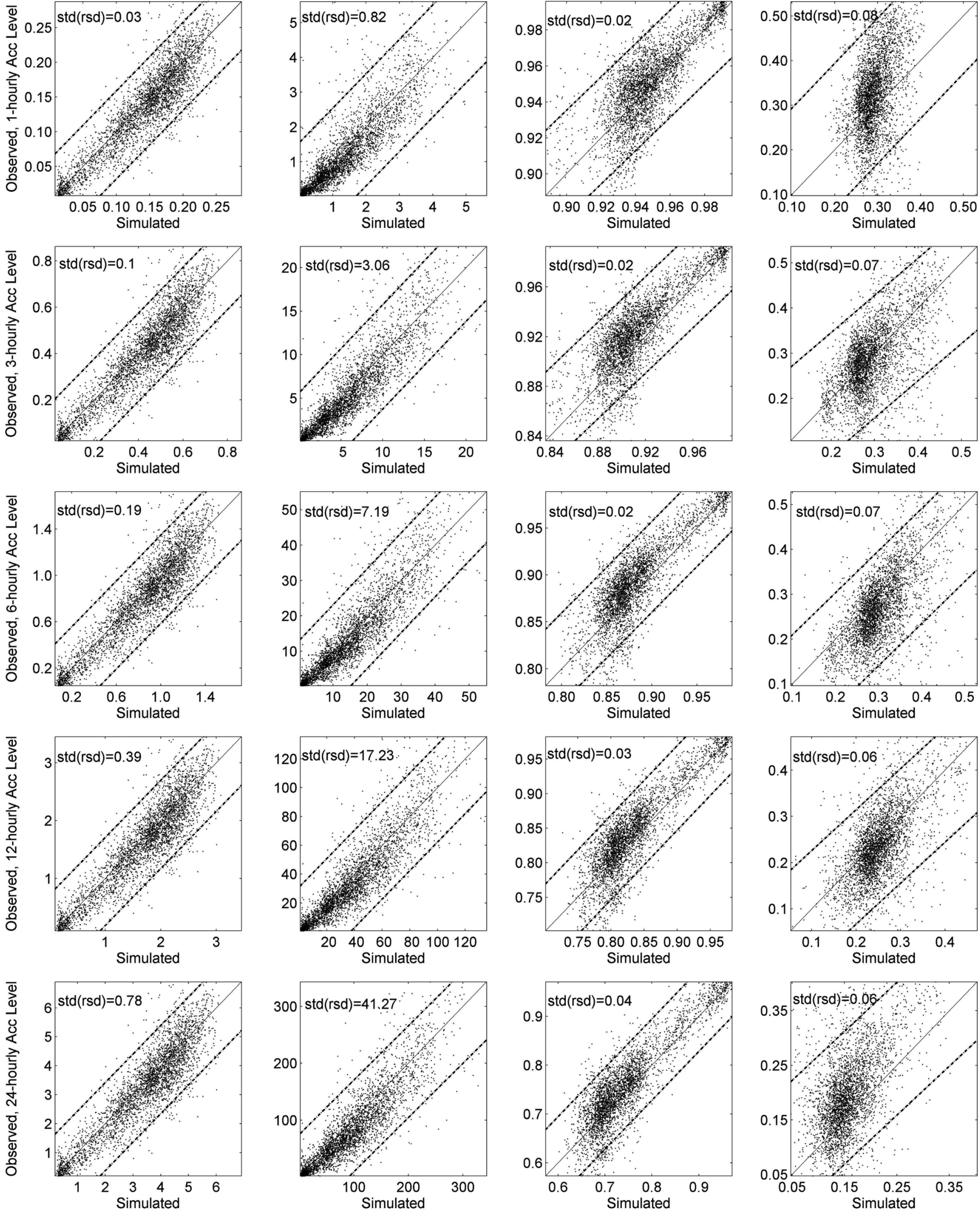

Fig. 9. Mean $\left(\mathrm{mm} \mathrm{hr}^{-1}\right)$, variance $\left(\mathrm{mm}^{2} \mathrm{hr}^{-2}\right)$, probability of zero rainfall and lag-1 autocorrelation coefficient of the observed precipitation (y-axis) vs. those calculated from the cross-validated parameters (x-axis) at various accumulation intervals for the month of May. The dotted lines correspond to the prediction interval with $95 \%$ confidence. 
Kim et al.

Table 4. Mean and standard deviation of the residaul between the observed rainfall statistics and the simulated rainfall statistics produced from the parameter maps.

\begin{tabular}{|c|c|c|c|c|c|}
\hline \multicolumn{2}{|c|}{ Accumulation Level } & Mean & Variance & Lag-1 & Probability of \\
\hline \multirow{2}{*}{ 1-hour } & Mean & 0.00506 & 0.0753 & -0.0320 & -0.00215 \\
\hline & Stdev & 0.0322 & 0.820 & 0.0828 & 0.0151 \\
\hline \multirow{2}{*}{ 3-hours } & Mean & 0.0152 & 0.287 & 0.00636 & -0.0101 \\
\hline & Stdev & 0.0965 & 3.049 & 0.0694 & 0.0198 \\
\hline \multirow{2}{*}{ 6-hours } & Mean & 0.0304 & 0.850 & 0.0313 & -0.00919 \\
\hline & Stdev & 0.193 & 7.17 & 0.0651 & 0.0244 \\
\hline \multirow{2}{*}{ 12-hours } & Mean & 0.0607 & 3.18 & 0.0149 & -0.00793 \\
\hline & Stdev & 0.386 & 17.2 & 0.0632 & 0.0309 \\
\hline \multirow{2}{*}{ 24-hours } & Mean & 0.1214 & 10.4 & -0.0398 & -0.0115 \\
\hline & Stdev & 0.772 & 41.14 & 0.0621 & 0.0422 \\
\hline
\end{tabular}

consistent parameter sets at neighboring gauges which enables capture of the correct, thus smooth spatial pattern of the parameters. This study applied 2 approaches to resolve this issue: (1) the one in which an anchor gauge is chosen and the parameter set at the neighboring gauge with the lowest Euclidean distance to the parameter set of the anchor gauge is chosen iteratively; and (2) the one in which the parameter estimation range is narrowed down according to the cross-validation result. Unfortunately, the first approach did not reduce the impact of the multi-modality well regardless of its solid logic. This is primarily because the parameter set selection process converges to an identical path regardless of the choice of different anchor gauge once the algorithm goes through the gauge with only one parameter set with high objective function value estimated at different modes in the parameter space, or simply a "bad" gauge. However, it is expected that this approach will reduce the impact of modality if such bad gauges are removed and the selection process is manually controlled with caution, which was out of the scope of this study due to the large size of data to treat.

In the meantime the effect of the second approach was significant. Table 2 compares the regression equations and the $\mathrm{R}^{2}$ values of the fit between the estimated parameter set and the cross-validated parameter set before and after the parameter range adjustment through cross-validation. Note that the slope and $\mathrm{R}^{2}$ values corresponding to the case in which the parameter space was narrowed are significantly higher than those in the original case, which indicates higher spatial correlation of the parameters. This is because the parameter sets that differ significantly from those of the neighboring gauge were not produced from the beginning because those are located out of the parameter range redefined through cross-validation, and thus were not included in the spatial interpolation process.

\section{SUMMARY AND CONCLUSIONS}

Seventy-two maps of the six parameters of the MBLRP stochastic rainfall generation model for each of the 12 months of the year were generated. These maps allow MBLRP model implementation at any location in the contiguous United States without having to calibrate and validate the model each time. The parameters were estimated at 3444 NCDC rain gauges by matching rainfall statistics (i.e., mean, variance, probability of zero rainfall and lag-1 autocorrelation coefficient) at different rainfall accumulation levels (i.e., 1, 3, 12 and 24 hours). The parameters obtained at the gauges were then interpolated using the Ordinary Kriging technique to generate surface maps.

Parameters $\lambda$ and $\mu$ were identified to have clear regional patterns, while $\phi$ and $\kappa$ had less clear yet discernible spatial tendencies. On the contrary, parameters $\alpha$ and $v$ did not show a clear pattern over space presumably because the lag-1 autocorrelation coefficient, to which they are highly sensitive, does not have a clear regional tendency either. Seasonality of the parameters appeared to depend on location and some parameters showed strong time dependence in some regions and no dependence in others.

The parameter maps were cross-validated to assess the validity of the Ordinary Kriging interpolation. It was observed that the synthetic rainfall time series statistics generated with parameters obtained from the maps developed here matched well the means, variances and probabilities of zero rainfall (except for a small number of low probabilities of zero rainfall) of observed rainfall time series, but not the lag-1 autocorrelation coefficients (whose higher values were underestimated and lower values, overestimated). A study of the relevance of matching the lag- 1 autocorrelation coefficient, when using synthetic rainfall in complex 
hydrologic applications, is beyond the scope of this article but a matter currently being researched by the authors. Even though mismatches in all statistics were found, according to the value of the standard deviation of the residuals, only the lag-1 autocorrelation coefficient is of concern. For this statistic the location of the gauges where the mismatch was more pronounced coincided in part with the driest parts of the country. Likewise, the fact that gauges in the northwest coast have some of the greatest residuals for all statistics seems to respond to high spatial variability in the area and the limitations of the interpolation technique to capture it with the existing gauge network. In this context, classifying the study area into smaller sub-regions based on the spatial variability of the parameters and applying the optimal interpolation technique for each sub-region separately may enhance the result.

Our map of $\lambda$ for the month of May was compared with that developed by Hawk and Eagleson (1992) and similar regional patterns were found, with similar low and high values in very much the same areas. Our map, however, is more complex in its shapes, most likely because of the significantly larger number of rain gauges used to develop it. Maps of the other parameters were not compared because their values involved the effect of multimodality and should be taken as a package and not individually.

Overall, it was observed that model parameters and storm and rain cell characteristics associated to observable physical variables were consequently, less affected by the multi-modality of calibration and showed stronger regional patterns. Other model parameters and storm and rain cell characteristics showed less well defined spatial patterns, most likely because the error in any of them can be compensated by the error in others.

Acknowledgements This work was supported by the Hongik University new faculty research support fund.

\section{REFERENCES}

Bo, Z., S. Islam, and E. A. B. Eltahir, 1994: Aggregationdisaggregation properties of a stochastic rainfall model. Water Resour. Res., 30, 3423-3435, doi: 10.1029/ 94WR02026. [Link]

Cameron, D., K. Beven, and J. Tawn, 2001: Modelling extreme rainfalls using a modified random pulse BartlettLewis stochastic rainfall model (with uncertainty). $A d v$. Water Resour., 24, 203-211, doi: 10.1016/S0309-1708 (00)00042-7. [Link]

Chandler, R. E., 1997: A spectral method for estimating parameters in rainfall models. Bernoulli, 3, 301-322.

Cho, H., D. Kim, F. Olivera, and S. D. Guikema, 2011: Enhanced speciation in particle swarm optimization for multi-modal problems. Eur. J. Oper. Res., 213, 15-23, doi: 10.1016/j.ejor.2011.02.026. [Link]
Choi, J., S. A. Socolofsky, and F. Olivera, 2008: Hourly disaggregation of daily rainfall in Texas using measured hourly precipitation at other locations. J. Hydrol. Eng., 13, 476-487, doi: 10.1061/(ASCE)1084-0699(20 08)13:6(476). [Link]

Cowpertwait, P. S. P., 1998: A Poisson-cluster model of rainfall: some high-order moments and extreme values. Proc. R. Soc. Lond. A, 454, 885-898, doi: 10.1098/rspa. 1998.0191. [Link]

Cowpertwait, P. S. P., P. E. O'Connell, A. V. Metcalfe, and J. A. Mawdsley, 1996a: Stochastic point process modelling of rainfall. I. Single-site fitting and validation. J. Hydrol., 175, 17-46, doi: 10.1016/S0022-1694 (96)80004-7. [Link]

Cowpertwait, P. S. P., P. E. O'Connell, A. V. Metcalfe, and J. A. Mawdsley, 1996b: Stochastic point process modelling of rainfall. II. Regionalisation and disaggregation. J. Hydrol., 175, 47-65, doi: 10.1016/S00221694(96)80005-9. [Link]

Cox, D. R. and V. S. Isham, 1988: A simple spatial-temporal model of rainfall. Proc. R. Soc. Lond. A, 415, 317-328, doi: 10.1098/rspa.1988.0016. [Link]

Econopouly, T. W., D. R. Davis, and D. A. Woolhiser, 1990: Parameter transferability for a daily rainfall disaggregation model. J. Hydrol., 118, 209-228, doi: 10. 1016/0022-1694(90)90259-Z. [Link]

Glasbey, C. A., G. Cooper, and M. B. McGehan, 1995: Disaggregation of daily rainfall by conditional simulation from a point-process model. J. Hydrol., 165, 1-9, doi: 10.1016/0022-1694(94)02598-6. [Link]

Gyasi-Agyei, Y., 1999: Identification of regional parameters of a stochastic model for rainfall disaggregation. J. Hydrol., 223, 148-163, doi: 10.1016/S0022-1694 (99)00114-6. [Link]

Gyasi-Agyei, Y. and G. Willgoose, 1997: A hybrid model for point rainfall modeling. Water Resour. Res., 33, 1699-1706, doi: 10.1029/97WR01004. [Link]

Gyasi-Agyei, Y. and S. M. P. B. Mahbub, 2007: A stochastic model for daily rainfall disaggregation into fine time scale for a large region. J. Hydrol., 347, 358-370, doi: 10.1016/j.jhydrol.2007.09.047. [Link]

Hawk, K. and P. S. Eagleson, 1992: Climatology of station storm rainfall in the continental United States: Parameters of the Bartlett-Lewis and Poisson rectangular pulses models. Ralph M. Parsons Laboratory, Massachusetts Institute of Technology, Cambridge, Massachusetts, USA.

Hershenhorn, J. and D. A. Woolhiser, 1987: Disaggregation of daily rainfall. J. Hydrol., 95, 299-322, doi: 10.10 16/0022-1694(87)90008-4. [Link]

Islam, S., D. Entekhabi, R. L. Bras, and I. Rodriguez-Iturbe, 1990: Parameter estimation and sensitivity analysis for the modified Bartlett-Lewis rectangular pulses model of rainfall. J. Geophys. Res., 95, 2093-2100, doi: 10. 
1029/JD095iD03p02093. [Link]

Journel, A. G. and Ch. J. Huijbregts, 1978: Mining Geostatistics, Academic Press, London, doi: 10.1016/00167142(81)90062-4. [Link]

Khaliq, M. N. and C. Cunnane, 1996: Modelling point rainfall occurrences with the modified Bartlett-Lewis rectangular pulses model. J. Hydrol., 180, 109-138, doi: 10.1016/0022-1694(95)02894-3. [Link]

Kim, D. and F. Olivera, 2012: Relative importance of the different rainfall statistics in the calibration of stochastic rainfall generation models. J. Hydrol. Eng., 17, 368-376, doi: 10.1061/(ASCE)HE.1943-5584.0000453. [Link]

Kim, D., F. Olivera, and H. Cho, 2013: Effect of the interannual variability of rainfall statistics on stochastically generated rainfall time series: Part 1. Impact on peak and extreme rainfall values. Stoch. Environ. Res. Risk Assess., in press, available at http://link.springer.com/ article/10.1007\%2Fs00477-013-0696-z.

NCDC (National Climatic Data Center), 2011a: Surface Data Daily, National Climatic Data Center (NCDC) - National Oceanic and Atmospheric Administration (NOAA), available at http://www.ncdc.noaa.gov/oa/climate/climatedata.html\#daily, as of May 8, 2013.

NCDC (National Climatic Data Center), 2011b: Precipitation Data, National Climatic Data Center (NCDC) - National Oceanic and Atmospheric Administration (NOAA), available at http://www.ncdc.noaa.gov/oa/climate/climatedata.html\#hourly, as of May 8, 2013

Onof, C. and H. S. Wheater, 1994a: Improved fitting of the Bartlett-Lewis rectangular pulse model for hourly rainfall. Hydrol. Sci. J., 39, 663-680, doi: 10.1080/02
626669409492786. [Link]

Onof, C. and H. S. Wheater, 1994b: Improvements to the modelling of British rainfall using a modified random parameter Bartlett-Lewis rectangular pulse model. $J$. Hydrol., 157, 177-195, doi: 10.1016/0022-1694(94)90 104-X. [Link]

Onof, C., D. Faulkner, and H. S. Wheater, 1996: Design rainfall modelling in the Thames catchment. Hydrol. Sci. J., 41, 715-733, doi: 10.1080/026266696094915 41. [Link]

Onof, C., R. E. Chandler, A. Kakou, P. Northrop, H. S. Wheater, and V. Isham, 2000: Rainfall modelling using Poisson-cluster processes: A review of developments. Stoch. Environ. Res. Risk Assess., 14, 384-411, doi: 10.1007/s004770000043. [Link]

Rodriguez-Iturbe, I., D. R. Cox, and V. Isham, 1987: Some models for rainfall based on stochastic point processes. Proc. R. Soc. Lond. A, 410, 269-288, doi: 10.1098/rspa. 1987.0039. [Link]

Rodriguez-Iturbe, I., D. R. Cox, and V. Isham, 1988: A point process model for rainfall: Further developments. Proc. R. Soc. Lond. A, 417, 283-298. doi: 10.1098/rspa. 1988.0061. [Link]

Socolofsky, S., E. E. Adams, and D. Entekhabi, 2001: Disaggregation of daily rainfall for continuous watershed modeling. J. Hydrol. Eng., 6, 300-309, doi: 10.1061/ (ASCE)1084-0699(2001)6:4(300). [Link]

Verhoest, N., P. A. Troch, and F. P. D. Troch, 1997: On the applicability of Bartlett-Lewis rectangular pulses models in the modeling of design storms at a point. J. Hydrol., 202, 108-120, doi: 10.1016/S0022-1694(97)00 060-7. [Link] 